\title{
Effect of GnRH antagonist on follicular development and uterine biophysical profile in controlled ovarian stimulation
}

\author{
Bhawana Tiwary*, Lakhbir Dhaliwal, Shalini Gainder
}

\begin{abstract}
Department of Obstetrics \& Gynaecology, Post Graduate Institute of Medical Education and Research, Chandigarh, Punjab, India
\end{abstract}

Received: 12 December 2014

Accepted: 03 January 2015

*Correspondence:

Dr. Bhawana Tiwary,

E-mail: bhawana.tiwary@gmail.com

Copyright: (C) the author(s), publisher and licensee Medip Academy. This is an open-access article distributed under the terms of the Creative Commons Attribution Non-Commercial License, which permits unrestricted non-commercial use, distribution, and reproduction in any medium, provided the original work is properly cited.

\begin{abstract}
Background: Objective of current study was to assess the effect of GnRH antagonist on follicular development, premature luteinization, uterine biophysical profile and pregnancy rate in controlled ovarian stimulation with clomiphene and gonadotropins for intrauterine insemination in women with unexplained infertility.

Methods: Randomised controlled trial. Minimal stimulation protocol with or without GnRH antagonist was compared. Setting: Infertility clinic, PGIMER, Chandigarh. Patients: Couples with unexplained infertility, age of female partner between 20-39 years. Intervention: $\mathrm{GnRH}$ antagonist $0.25 \mathrm{mg}$ since follicle size $14 \mathrm{~mm}$ till hCG administration. Main outcome measures: Follicle characteristics, premature luteinisation, uterine biophysical profile and pregnancy rate.

Results: The mean number of follicles recruited in group A was $2.32 \pm 1.01$ while that in group B (receiving GnRH antagonist) it was $4.10 \pm 1.69$. Statistically significant increase in total biophysical profile score was observed in periovulatory phase in the antagonist group. $40 \%$ women in group A had premature luteinization whereas only $4 \%$ women in group B suffered from premature luteinization. $20 \%$ women who received GnRH antagonist conceived against only $6 \%$ in group $\mathrm{A}$, this difference however was not statistically significant

Conclusions: GnRH antagonist has a role in increasing the number of follicles recruited. Furthermore, GnRH antagonist can improve the total uterine biophysical profile score by improving the endometrial thickness, endometrial pattern, blood flow and decreasing the impedance to the blood flow in uterine artery. The drug can potentially help in improving pregnancy rates by decreasing the rate of premature luteinisation.
\end{abstract}

Keywords: Minimal stimulation, Intrauterine insemination, GnRH antagonist, Uterine biophysical profile

\section{INTRODUCTION}

In women with unexplained infertility, the use of Controlled Ovarian Stimulation (COS) along with IUI results in a comparable cumulative pregnancy rate to IVF and is a more cost effective approach. ${ }^{1}$ It has been calculated that $24 \%$ of stimulated cycles may undergo premature luteinisation. ${ }^{2}$ which is unwanted and could lead to cycle cancellation and patient distress. Clomiphene and gonadotropins in combination do have an unpredictable ovarian reaction and cause premature Luteinizing Hormone (LH) surge in nearly $20 \%$ of cases. ${ }^{3}$ It has been suggested in IVF cycles that GnRH antagonist prevents premature LH surge. GnRH antagonists offer several potential advantages over agonists. ${ }^{4}$

Disorders of endometrial receptivity and implantation failure represent an important cause of unexplained infertility. Need for combining parameters in order to predict the uterine receptivity was realized as none of the individual parameters could accurately predict the same. 
Michael Applebaum came up with a concept of evaluating uterine receptivity by means of a score ascertained on basis of assessment of endometrial thickness, appearance, blood flow, myometrial contractions, pulsatility index of uterine arteries, myometrial echogenicity and myometrial blood flow. This was termed as 'uterine scoring system for reproduction'.5 A similar concept has been pursued for scoring by other investigators, who have proposed a uterine score as a predictor of implantation. ${ }^{6-9}$ However, current data regarding the parameters evaluating uterine receptivity remain inconclusive. The endometrial development after $\mathrm{GnRH}$ antagonist mimics the natural endometrium more closely than after GnRH agonist. However, till date, effect of various ovarian stimulation drugs on 'uterine biophysical profile' has not been evaluated in detail.

Given this background, the present study was undertaken to evaluate the effect of $\mathrm{GnRH}$ antagonist on follicular characteristics, prevention of premature luteinisation, uterine biophysical profile score and pregnancy outcomes.

\section{METHODS}

This was a prospective randomised controlled trial performed from July 2011 to July 2012 in 100 patients with unexplained infertility in infertility clinic of department of obstetrics \& gynaecology, PGIMER Chandigarh. Each patient gave written informed consent and clearance from the ethical committee of the institute was sought.

\section{Inclusion criteria}

Criteria for diagnosis of unexplained infertility:

- No evidence of anatomic or functional disorder of the reproductive tract on history and examination

- $\quad$ Age of female partner 20-39 years

- Infertility of more than one year

- Regular menstrual cycles

- Normal prolactin and thyroid function tests in early follicular phase

- Normal tubal, uterine and peritoneal anatomy determined by hysterosalpingography and laparoscopy

- Baseline FSH/LH levels within normal range

- Normal semen analysis within last 2 months

\section{Exclusion criteria}

Couples with any of the following factors were excluded from the study

- Known cause of infertility

- Pelvic inflammatory disease
- History of ovarian hyperstimulation with gonadotropins

- History of ovarian malignancy in the family

\section{Study protocol}

After thorough evaluation, counselling and taking written informed consent, 100 women with unexplained infertility were divided into two groups according to random number table who received either of two ovarian stimulation protocols:

Group A (Control group): $(n=50)$ received minimal ovarian stimulation protocol.

Group B (Study group): $(\mathrm{n}=50)$ received minimal ovarian stimulation along with GnRH antagonist. In order to maintain uniformity Cetrorelix was used as $\mathrm{GnRH}$ antagonist in each subject.

\section{Ovarian stimulation protocol}

Minimal stimulation protocol was used for ovarian stimulation. To start with, 150 IU of urinary Follicular Stimulating Hormone (FSH) was administered IM on day 2 of their cycle followed by clomiphene citrate $100 \mathrm{mg}$ daily from day 3 to day 7 . Urinary Human Menopausal Gonadotropin (HMG) $150 \mathrm{IU}$ was given on day 8. TVS was performed on day 9 to assess ovarian response and was repeated as per response every 2-3 days and further more gonadotropins, if needed, were given according to the response assessed on follicular monitoring until the leading follicles reach mean diameter of $\geq 17 \mathrm{~mm}$. Then, 5000 IU Human Chorionic Gonadotropin (HCG) was given IM and IUI was performed 36 hours later.

\section{Study group}

The same stimulation protocol was followed and monitored for follicular recruitment and growth. When the leading follicles reached a diameter of $14 \mathrm{~mm}, 0.25$ $\mathrm{mg}$ cetrorelix in $0.5 \mathrm{ml}$ aqueous solution was given daily till the dominant follicle size of $18 \mathrm{~mm}$ was achieved, subsequently human chorionic gonadotropin (hCG) 5000 IU was administered to trigger ovulation and IUI was performed 36 hours later.

\section{Assessment of premature luteinization}

On the day of hCG administration, serum LH, progesterone and estradiol was measured in both the groups. LH level more than or equal to $10 \mathrm{IU} / \mathrm{L}$ or Progesterone more than or equal to $2 \mathrm{ng} / \mathrm{ml}$ was used for diagnosis of premature luteinization.

\section{Uterine biophysical profile}

All subjects were examined during one cycle. The sonographic assessment was performed by the same investigator using the same parameters so as to eliminate 
any interobserver variation. Transvaginal ultrasonography was performed using a ATL-HDI 1500 ultrasound machine using 5-9 Mhz transducer for Bmode and color imaging as well as pulsed Doppler spectral analysis. Identical ultrasound and Doppler settings were used in all women. All subjects underwent the transvaginal ultrasonography in a quite location between $8 \mathrm{a} . \mathrm{m}$. to $10 \mathrm{a} . \mathrm{m}$. to reduce any variation due to circardian rhythm. The ultrasounds were conducted during designated phases of the cycle, baseline (day 2-3), periovulatory (day 11-13). The following morphometric and Doppler assessment of the endometrium suggested as the 'uterine biophysical profile' by Applebaum. ${ }^{5}$ were studied:

1. Endometrial thickness

2. Endometrial layering (pattern)

3. Blood flow in the endometrium using color Doppler technique

4. Uterine artery blood flow measured by pulsatility index

5. Myometrial echogenicity

Table 1: Applebaum modified uterine biophysical profile score.

\begin{tabular}{|c|c|c|c|}
\hline \multirow[b]{2}{*}{ Parameter } & \multicolumn{3}{|l|}{ Score } \\
\hline & $\begin{array}{l}\text { Baseline } \\
\text { (d 2-3) }\end{array}$ & $\begin{array}{l}\text { Periovulatory } \\
\text { (d 11-13) }\end{array}$ & $\begin{array}{l}\text { Midluteal } \\
\text { (d 21-23) }\end{array}$ \\
\hline \multicolumn{4}{|c|}{ Endometrial thickness } \\
\hline$<7 \mathrm{~mm}$ & 1 & 1 & 1 \\
\hline $7-9 \mathrm{~mm}$ & 2 & 2 & 2 \\
\hline $10-14 \mathrm{~mm}$ & 3 & 3 & 3 \\
\hline$>14 \mathrm{~mm}$ & 1 & 1 & 1 \\
\hline \multicolumn{4}{|c|}{ Endometrial layering } \\
\hline No layering & 0 & 0 & 0 \\
\hline $\begin{array}{l}\text { Hazy } 5 \text { line } \\
\text { appearance }\end{array}$ & 2 & 2 & 2 \\
\hline $\begin{array}{l}\text { Distinct } 5 \text { line } \\
\text { appearance }\end{array}$ & 3 & 3 & $1 *$ \\
\hline $\begin{array}{l}\text { Hyperechoic thick } \\
\text { endometrial }\end{array}$ & 1 & 1 & $3 *$ \\
\hline \multicolumn{4}{|c|}{ Endometrial blood flow within zone 3} \\
\hline Absent & 0 & 0 & 0 \\
\hline Present but sparse & 2 & 2 & 2 \\
\hline $\begin{array}{l}\text { Present } \\
\text { multifocally }\end{array}$ & 5 & 5 & 5 \\
\hline \multicolumn{4}{|c|}{ Uterine artery Doppler flow evaluation } \\
\hline $\mathrm{PI}>2.5$ & 0 & 0 & 0 \\
\hline PI 2.2-2.49 & 1 & 1 & 1 \\
\hline $\mathrm{PI}<2.2$ & 2 & 2 & 2 \\
\hline \multicolumn{4}{|c|}{ Myometrial echogenicity } \\
\hline $\begin{array}{l}\text { Coarse/irregular } \\
\text { echogenicity }\end{array}$ & 1 & 1 & 1 \\
\hline $\begin{array}{l}\text { Relatively } \\
\text { homogeneous } \\
\text { echogenicity }\end{array}$ & 2 & 2 & 2 \\
\hline
\end{tabular}

Package for Social Sciences (SPSS Inc., Chicago, IL, version 15.0 for Windows). All quantitative variables e.g. age, height, weight, type and duration of infertility were estimated using measures of central location mean, median and measures of dispersion: standard deviation and standard error. For normally distributed data means of height, weight, duration infertility of two groups were compared using student t-test. For skewed data, Mann Whitney test was applied. Qualitative or categorical variables were described as frequencies and proportions. Proportions were compared using Chi square or Fisher's exact test whichever was applicable for two groups as well as for within groups. All statistical tests were twosided and were performed taking $\mathrm{P}$ value $<0.05$ as statistically significant.

\section{RESULTS}

A total of 100 patients with unexplained infertility were included in the study and were randomly allocated into either of the two groups as per the random table number. No significant difference was observed between the two characteristics were concerned as shown in Table 2 .

As shown in Table 3, the mean number of follicles in group B was $4.10 \pm 1.69$ which was significantly greater than that in group A $[2.32 \pm 1.01 \quad(\mathrm{P}<0.001)]$. Significantly more number of ampoules of gonadotropins were required in the study group as compared to control. On an average 3 ampoules of gonadotropin (150 IU groups as far as the demographic and baseline 
HMG) were used in GnRH antagonist group whereas the other group required only 1 ampoule of $\mathrm{HMG}$ on an average $(\mathrm{P}<0.001)$.

Mean progesterone and LH levels on day of hCG administration was significantly more in Control group than in those receiving cetrorelix $(\mathrm{P}<0.001)$.

Premature luteinization occurred in $40 \%$ of women in the Control group whereas only in $4 \%$ in the Study group. None of the patients experienced severe OHSS.

The prevalence of mild OHSS was higher in the control group $(4 \%)$ than in the study group $(2 \%)$ though this difference was not statistically significant.

Table 2: Comparison of baseline characteristics of patients.

\begin{tabular}{|lll|}
\hline & $\begin{array}{l}\text { Group A } \\
\text { (Control) }\end{array}$ & $\begin{array}{l}\text { Group B } \\
\text { (Study) }\end{array}$ \\
\hline Mean age (years) & $29.50 \pm 3.99$ & $29.36 \pm 3.95$ \\
\hline $\begin{array}{l}\text { Duration of infertility } \\
\text { (years) }\end{array}$ & $6.7 \pm 3.59$ & $6.1 \pm 3.63$ \\
\hline $\begin{array}{l}\text { Type of infertility } \\
\text { (Primary) }\end{array}$ & $33(66 \%)$ & $38(76 \%)$ \\
\hline
\end{tabular}

Table 3: Comparison of cycle characteristics between the groups.

\begin{tabular}{|llll|} 
& $\begin{array}{l}\text { Control } \\
\text { group }\end{array}$ & $\begin{array}{l}\text { Study } \\
\text { group }\end{array}$ & $\begin{array}{l}\text { P } \\
\text { value }\end{array}$ \\
\hline $\begin{array}{l}\text { Mean ampoules } \\
\text { of gonadotropins }\end{array}$ & $1.16 \pm 0.51$ & $3.12 \pm 1.46$ & $<0.001$ \\
\hline $\begin{array}{l}\text { Mean } \\
\text { progesterone } \\
\text { (ng/ml) }\end{array}$ & $6.073 \pm 10.51$ & $1.021 \pm 0.640$ & 0.000 \\
\hline $\begin{array}{l}\text { Mean follicle } \\
\text { number }\end{array}$ & $2.32 \pm 1.01$ & $4.10 \pm 1.69$ & $<0.001$ \\
\hline $\begin{array}{l}\text { Mean serum LH } \\
\text { (IU/L) }\end{array}$ & $8.39 \pm 3.48$ & $5.31 \pm 3.86$ & 0.001 \\
\hline $\begin{array}{l}\text { Premature } \\
\text { luteinisation }\end{array}$ & $20(40 \%)$ & $2(4 \%)$ & $<0.001$ \\
\hline $\begin{array}{l}\text { Ovarian } \\
\text { hyperstimulation }\end{array}$ & $2(4 \%)$ & $1(2 \%)$ & 1 \\
\hline
\end{tabular}

As shown in Table 4, it was observed that the mean total score of study group receiving cetrorelix was 10.18 and it was only 7.88 in the control group $(\mathrm{P}<0.001)$. During the periovulatory phase mean scores for endometrial blood flow in zone 3, pulsatility index, endometrial thickness and endometrial layering were significantly higher in the Study group. The mean scores of various ultrasound and Doppler parameters has also been depicted in graphical form in Figure 1.

Table 4: Comparison of uterine biophysical profile score.

\begin{tabular}{|llllll|} 
& $\begin{array}{l}\text { Endometrial } \\
\text { pattern }\end{array}$ & $\begin{array}{l}\text { Endometrial } \\
\text { blood flow }\end{array}$ & UA PI & $\begin{array}{l}\text { Endometrial } \\
\text { thickness }\end{array}$ & $\begin{array}{l}\text { Total uterine } \\
\text { biophysical } \\
\text { profille score }\end{array}$ \\
\hline Group A (Control) & $2.76 \pm 0.555$ & $2.86 \pm 1.818$ & $2.3246 \pm 0.79$ & $1.66 \pm 0.626$ & $7.88 \pm 2.2$ \\
\hline Group B (Study) & $3.00 \pm 0$ & $4.16 \pm 1.361$ & $1.8752 \pm 0.499$ & $2.14 \pm 0.535$ & $10.18 \pm 1.68$ \\
\hline P value & 0.001 & $<0.001$ & 0.003 & 0.000 & $<0.001$ \\
\hline
\end{tabular}

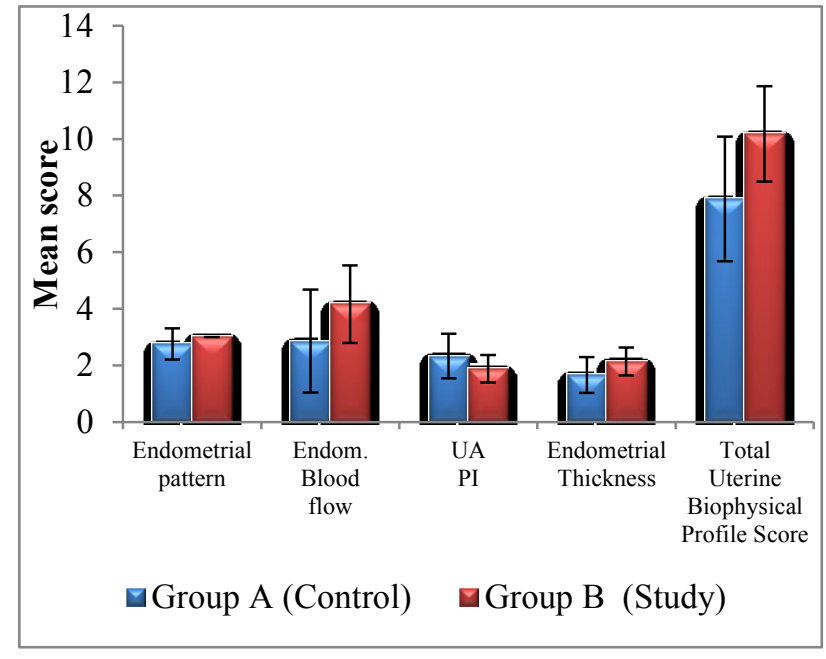

Figure 1: Comparison of uterine biophysical profile score.

\section{Pregnancy outcomes}

Out of the thirteen pregnancies, 3 were among control group while 10 were in women receiving $\mathrm{GnRH}$ antagonist as discussed earlier. Unfortunately, one patient out of these 13 (from the control group) had missed abortion. Rest of them had successful pregnancies.

\section{Analysis of total scores to predict chances of pregnancy}

The total uterine biophysical profile score in the periovulatory phase was then analysed to predict the chances of pregnancy. None of the women with a score of $<5$ conceived. 43 women demonstrated a score between 6-10 out of whom 2 conceived. The most favorable chance of conception was with a score of 11-15 during the periovulatory phase.11 women out of 55 having score 11-15 conceived. The chances of pregnancy with this score of $11-15$ was $20 \%$ as shown in Table 5. 
Table 5: Pregnancy distribution as per the periovulatory total biophysical score.

\begin{tabular}{|llll|}
\hline $\begin{array}{l}\text { Biophysical } \\
\text { profile score }\end{array}$ & $\begin{array}{l}\text { No. of } \\
\text { cases }\end{array}$ & Pregnant & \%Pregnant \\
\hline $0-5$ & 2 & 0 & - \\
\hline $6-10$ & 43 & 2 & 4.65 \\
\hline $11-15$ & 55 & 11 & 20 \\
\hline
\end{tabular}

Though this study showed several benefits of use of $\mathrm{GnRH}$ antagonist in stimulation protocols, it has to be admitted that overall cycles involving the use of $\mathrm{GnRH}$ antagonist were costlier. It was observed that in the group receiving GnRH antagonist approximately 3790 rupees was spent while in Control group only 1355 rupees was required. This difference was highly significant $(\mathrm{P}=$ $0.000)$.

\section{DISCUSSION}

Unexplained infertility is responsible for 10 to $15 \%$ cases of infertility. Some cases of unexplained infertility may result from defective uterine receptivity leading to implantation failure, therefore there is a need to assess the endometrium accurately for defects that could preclude implantation. Intrauterine insemination (IUI) combined with Controlled Ovarian Stimulation (COS) is a widely practiced method in such cases and is a more cost effective approach when compared to IVF. Premature luteinization results in negative effect on endometrium and oocyte quality and hence has a deleterious effect on IUI cycles. GnRH analogues have been shown to lower the incidence of premature LH surge and thus improve IUI outcomes in several studies. GnRH antagonist is unique in its properties as it does not have the flare effect seen with GnRH agonist. Hence, it is more physiological and can improve the success rate of COS-IUI cycles.

The purpose of this preliminary study was to determine if the inclusion of a GnRH antagonist (cetrorelix) in minimal ovarian stimulation (MOS) with clomiphene citrate and gonadotropins for IUI could significantly increase the number of mature follicles and, by extension, improve pregnancy rates, since these two parameters are known to be positively correlated. The rationale for this hypothesis was based on the capacity of the GnRH antagonist to rapidly inhibit $\mathrm{LH}$ release by the gonadotrophs and thereby control and avoid premature luteinization. ${ }^{10}$ As data from literature about different endometrial parameters was controversial, a score that takes into account various parameters rather than a single one was considered appropriate and hence we used the 'uterine biophysical profile score' devised by Applebaum. ${ }^{5}$ The hypothesis was that a non-receptive endometrium may have a role to play in cases of unexplained infertility and the uterine biophysical profile could be a rapid, non-invasive and simple method to assess the receptive state of the endometrium. Moreover it was proposed to study the effect of GnRH antagonist on these parameters and hence its role in improving the endometrial milieu. In the present study, the average follicular size in group A was $17.98 \pm 2.14 \mathrm{~mm}$ while in group B it was $17.52 \pm 2.02 \mathrm{~mm}$, the difference between the two groups being statistically insignificant. However, the number of follicles per cycle was higher in group B $(4.10 \pm 1.69)$ as compared to group A $(2.32 \pm 1.01)$, the difference being highly significant statistically ( $\mathrm{p}$ value $<0.001)$. This is in agreement with the observations made by Gomez-Palomares et al., the follicle number being 2.4 \pm 1.4 in GnRH antagonist group and $1.7 \pm 1.2$ in the control group in their study. ${ }^{11}$ However, Checa et al. observed no significant difference was found in number of follicles on administration of GnRH antagonist. ${ }^{12}$ The analysis of the results demonstrated that the score for all the individual parameters of 'uterine biophysical profile' were higher in group receiving $\mathrm{GnRH}$ antagonist. In the present study we studied various uterine parameters that affect the implantation and pregnancy rates and the changes observed in these parameters after administration of GnRH antagonist (cetrorelix). Results revealed that during the periovulatory phase, significantly more number of women in the cetrorelix group had higher endometrial thickness score of $\geq 2$ (46 versus 29 in the control group). This observation is further supported by a prospective randomized trial conducted in 2006 by Checa et al. In their study they found that cetrorelix significantly results in a thicker endometrium with an endometrial thickness of $9.9 \pm 1.88 \mathrm{~mm}$ as compared to $8.6 \pm 0.5 \mathrm{~mm}$ in the control group $(\mathrm{P}$ value $=0.001){ }^{12}$

The triple line appearance of the endometrium at the time of ovulation, because of luminal stromal density, has been described by authors as a prognostic factor for pregnancy in gonadotropin stimulated cycles. The present study showed a statistically significant difference between the endometrial pattern score between the two groups as all women who received cetrorelix had a welldefined distinct 5 line appearance (trilaminar pattern) whereas in the control group $20 \%$ women only had hazy trilaminar pattern or absolutely no layering.

Most investigators agree that a higher degree of endometrial perfusion shown by color and power Doppler indicated a receptive state of the endometrium. In the present study endometrial blood flow was multifocal in $72 \%$ women in the study group whereas in the control group, only $38 \%$ women had multifocal blood flow ( $\mathrm{P}=$ 0.001). Edi Osagie et al. ${ }^{13}$ in their multiparametric approach concluded that women with unexplained infertility had a consistent impairment of endometrial perfusion in all phases of the cycle. Till date, to the best of our knowledge there has been no controlled randomized study to assess the effect of GnRH antagonist on endometrial blood flow. However, several investigators have studied the role of endometrial blood flow in determining the outcome of ART. Chein et al. ${ }^{14}$ and $\mathrm{Wu}$ et al. ${ }^{15}$ investigated the correlation of blood flow detected by color Doppler sonography in endometrial - subendometrial unit with pregnancy outcome of IVF and demonstrated that the presence of 
both endometrial and subendometrial flow is indicative of good endometrial receptivity.

As far as the role of GnRH antagonist in improving chances of conception goes, literature has conflicting statements. In the present study 13 women became pregnant. Out of these 13 , three $(6 \%)$ conceived following conventional minimal stimulation protocol (clomiphene citrate + gonadotropins) and IUI whereas 10 $(20 \%)$ conceived from the study group in which $\mathrm{GnRH}$ antagonist was added from $14 \mathrm{~mm}$ follicle size onwards. Similar results were achieved by Gomez-Palomares et al. ${ }^{11}$ and Allegra et al. ${ }^{16}$ in IUI cycles with conventional stimulation protocol using gonadotropins. In comparison Lambalk et al. ${ }^{17}$ observed similar outcomes in terms of pregnancy rates in both the treatment and control groups $(12.6 \%$ versus $12 \%)$. A recent meta-analysis in $2008,{ }^{18}$ compared the clinical outcome in COS-IUI cycles using GnRH antagonist and it was concluded that pregnancy rate was improved with the use of GnRH antagonist as it decreases premature luteinization and allows for follicle growth. On compiling all the scores of individual parameters we computed a total biophysical profile score. It was seen in the present study that $66 \%$ women who were administered $\mathrm{GnRH}$ antagonist had a favorable score (11-15) whereas in the control group it was only in $18 \%$ cases. Thus, it was concluded that there was a statistically significant difference between the two groups in uterine score $(\mathrm{P}<0.001)$. As far as literature goes, no study demonstrating the effect of GnRH antagonist on 'uterine biophysical profile score' could be traced.

Hence, as suggested by Applebaum, ${ }^{5}$ the uterine biophysical profile can be used for making clinical decisions in women with unexplained infertility. In our knowledge this study is first of its kind to study systematically the effect of addition of GnRH antagonist to the ovarian stimulation cycles with clomiphene citrate on uterine biophysical profile score. This study further substantiates the fact that women who receive $\mathrm{GnRH}$ antagonist have decreased premature luteinization and improved chances of conception. Moreover, it was seen in the study that all the individual parameters as well as the total biophysical profile score was improved by the use of GnRH antagonist in COS-IUI cycles in women with unexplained infertility. The prediction of uterine receptivity based on the uterine biophysical profile was also attempted with the periovulatory total score emerging as an important predictor of the chances of getting pregnant. In future larger studies are required to further explore the effects of $\mathrm{GnRH}$ antagonist on various parameters of endometrial receptivity.

\section{ACKNOWLEDGEMENTS}

Special thanks to Dr. Sumitu Sahdev and Dr. Sujata of infertility clinic of PGIMER for their valuable assistance in creating a rapport with the subjects and thus making this study instrumental. We gratefully acknowledge the technical assistance of Mrs. Kusum Chopra, our statistician.
Funding: No funding sources

Conflict of interest: None declared

Ethical approval: The study was approved by the institutional ethics committee

\section{REFERENCES}

1. Goverde AJ, McDonell J, Vermeiden JP, Schats R, Rutten FF, Shoemaker J. Intrauterine insemination or in vitro fertilization in idiopathic subfertility and male subfertility: a randomized trial and cost effectiveness analysis. Lancet. 2000 Jan;355:13-8.

2. Ragni G, Somigliana E, Vegetti W. Timing of intrauterine insemination: where are we? Fertil Steril. 2004 Jul;82(1):25-6.

3. Klaus Feidler, Michael Ludwig. Use of clomiphene citrate in IVF and IVF/Intracytoplasmic sperm injection cycles. Fertil Steril. 2003 Dec;80(6):15213.

4. Olivennes F, Cunha-Filho JS, Fanchin R, Bouchard $\mathrm{P}$, Frydman R. The use of GnRH antagonists in ovarian stimulation. Hum Reprod Update. 2002 May-Jun;8(3):279-90.

5. Applebaum M. The uterine biophysical profile. Ultrasound Obstet Gynaecol. 1995 Jan;5(1):67-8.

6. Salle B, Bied-Damon V, Benchaib M, Desperes S, Gaucherand P, Rudigoz RC. Preliminary report of an ultrasonography and colour Doppler uterine score to predict uterine receptivity in an in vitro fertilization programme. Hum Reprod. 1998 Jun;13(6):1669-73.

7. Kupesic S, Bekavac I, Bjelos D, Kurjak A. Assessment of endometrial receptivity by transvaginal color Doppler and three-dimensional power Doppler ultrasonography in patients undergoing in vitro fertilization procedures. J Ultrasound Med. 2001 Feb;20(2):125-34.

8. Baruffi RL, Contart P, Mauri AL, Peterson C, Felipe $\mathrm{V}$, Garbellini E, et al. A uterine ultrasonographic scoring system as a method for the prognosis of embryo implantation. J Assist Reprod Genet. 2002 Mar;19(3):99-102.

9. Sohail S. The uterine biophysical profile scoring validity. J Coll Physicians Surg Pak. 2005 Sep;15(9):556-8.

10. Diedrich K, Diedrich C, Santos E, Zoll E, Al-Hasani $\mathrm{S}$, Reissmann $\mathrm{T}$, et al. Suppression of the endogenous luteinizing hormone surge by the gonadotropin-releasing hormone antagonist cetrorelix during ovarian stimulation. Hum Reprod. 1994 May;9(5):788-91.

11. Gomez-Palomares JL, Julia B, Acevedo-Martin B, Martinez-Burgos M, Hernandez ER, Ricciarelli E. Timing ovulation for intrauterine insemination with a GnRH antagonist. Hum Reprod. 2005 Feb;20(2):368-72.

12. Checa MA, Prat M, Robles A, Carreras R. Use of GnRH antagonist overcome the drawbacks of intrauterine insemination on weekends. Fertil Steril. 2006 Mar;85(3):573-7. 
13. Edi-Osagie EC, Seif MW, Aplin JD, Jones CJ, Wilson G, Lieberman BA. Characterizing the endometrium in unexplained and tubal factor infertility: a multiparametric investigation. Fertil Steril. 2004 Nov;82(5):1379-89.

14. Chein LW, Au HK, Chen PL, Xiao J, Tzeng Cr. Assessment of uterine receptivity by the endometrial - subendometrial blood flow distribution pattern in women undergoing in vitro fertilization-embryo transfer. Fertil Steril. 2002 Aug;78(2):245-51.

15. Wu HM, Chiang $\mathrm{CH}$, Huang HY, Chao AS, Wang HS, Soong YK. Detection of the subendometrial vascularization flow index by three-dimensional ultrasound may be useful for predicting the pregnancy rate for patients undergoing in vitro fertilization-embryo transfer. Fertil Steril. 2003 May;79(3):507-11.

16. Allegra A, Marino A, Coffaro F, Scaglione P, Scaglione F, Rizza G, et al. GnRH antagonist induced inhibition of the premature LH surge increases pregnancy rates in IUI stimulated cycles: a prospective randomized trial. Hum Reprod. 2007 Jan;22(1):101-8.

17. Lambalk CB, Leader A, Olivennes F, Fluker MR, Andersen AN, Ingerslev J, et al. Treatment with the $\mathrm{GnRH}$ antagonist ganirelix prevents $\mathrm{LH}$ rises and luteinization in stimulated intrauterine insemination: results of a double-blind, placebo-controlled, multicentric trial. Hum Reprod. 2006 March;21(3):632-9.

18. Kosmas I, Tatsioni A, Kolibianakis EM, Verproest W, Tournaye H, Van der Elst J, et al. Effects and clinical significance of GnRH antagonist administration for IUI timing in FSH superovulated cycles: a meta-analysis. Fertil Steril. 2008 Aug;90(2):367-72.

DOI: $10.5455 / 2320-1770$. ijrcog20150228

Cite this article as: Tiwary B, Dhaliwal L, Gainder S. Effect of GnRH antagonist on follicular development and uterine biophysical profile in controlled ovarian stimulation. Int J Reprod Contracept Obstet Gynecol $2015 ; 4: 157-63$ 